Twenty oil-fields of north-western Germany are associated with salt domes, fifteen being of the flank type and five of the crestal type. Six fields are located on anticlines ; for example, those of the Ems district. The source rocks are the main dolomite and the porous shale of the Middle Zechstein, the coral oolite of the Malm, the shell banks of the Wealden, the debris layers of the Neocomian, the chalk of the Upper Cretaceous, the sandstones of the Rhætic, the Lower Liassic, the Lower Dogger, Cornbrash, Valendis, and Lower Eocene. Almost all the fields are poor in gas content and subject to edge water drive. In 1946 the total production amounted to about $4,380,000$ barrels.

In April 1947, geophysical results of a general interest were obtained from the blowing-up of the fortifications of the island of Heligoland (see Nature, September 13, p. 350). The depths of the North German area of sedimentation were established as approximately $3 \cdot 1-6 \cdot 2$ miles, while the top of the sima near Göttingen was encountered at a depth of
17 miles, and at 25 miles at the edge of the Alps. The thickness of the continent, hitherto assumed as 37-62 miles, was thus considerably reduced; while fundamentally new knowledge of the major tectonic movements of the earth's crust was obtained.

Thirty-seven reports on the tectonics and palæography of Saxony, geophysical and petrographic methods of investigation, production engineering, and micro-palæontology afforded a comprehensive view of the state of German oil geology.

Many geologists were greatly stimulated by the meeting, and the synthesis between scientific research and its practical application was repeatedly emphasized. This synthesis alone has helped to achieve the results described during the meeting. A full report will be published in due course in the Zeitschrift der Deutschen Geologischen Gesellschaft.

An outcome of the meeting was the decision to found a Deutsche Gesellschaft für Mineralölwissenschaft and a Deutsche Geologische Gesellschaft for the British Zone.

W. RÜHL

\title{
THERMIONIC EMISSION FROM OXIDE-COATED CATHODES
}

$\mathrm{O}^{\mathrm{x}}$ XIDE-COATED cathodes have been used by the million for many years, but the explanation of the exact mechanism of the thermionic emission from them still presents many interesting physical prob. lems. The summer meeting in London on June 14, arranged by the Electronics Group of the Institute of Physics, on recent work on such cathodes was most opportune, since the war-time use of the cathodes under pulse conditions, and the influence of recent theories of the properties of barrier-layer rectifiers and semiconductors, have stimulated further experimental and theoretical work, and are leading to a revision of views previously held.

Dr. F. A. Vick, of the University of Manchester, began the opening paper by summarizing the position in 1939. Activated cathodes were believed to consist of a mixture of barium and strontium oxides on a metal (normally a nickel alloy) core. Near the surface, strontium oxide was thought to predominate, and adsorbed on the surface a layer of barium, of concentration depending on the equilibrium between diffusion towards the surface and electrolytic movement towards the core during current flow. The high efficiency of oxide cathodes was supposed to be due to the lowering of the effective surface potential barrier by the adsorbed barium $1,2,3,4$, analogous to the action of electro-positive layers on tungsten. Earlier workers had suggested ${ }^{5,8}$ that the observed electron emission is determined by the potential barrier at the core-oxide interface, but by 1939 the role of the core had been relegated to assisting in the dissociation of oxides to provide some free barium.

The war-time use of oxide cathodes in valves used for pulse work directed attention to the fact that the peak saturated current in microsecond pulses could be many times (for example, 100) the normal saturated current at the same nominal temperature. Sproull ${ }^{7}$ described careful experiments on the current-decay characteristics of the cathodes, with anode voltages kept constant for times varying between 100 and 2,000 microsec. and then switched off for times long enough for the cathode to recover. The saturation current rose to an initial high value and then decayed to an asymptote one-fifth to one-fifteenth of the initial value. Sproull suggested that as soon as the thermionic current starts to flow through the oxide, the concentration of the adsorbed barium layer commences to decrease from the equilibrium value under zero current to a new value depending on electrolytic movement through the oxide, and leading to a higher effective work function. Sproull inferred that electrolytic movement is easy through the oxide crystals but difficult across the crystal boundaries. Dr. Vick expressed the view that Sproull's theory is not the whole explanation of pulse effects, though some electrolytic movement of barium may be a contributory factor.

More recently, E. A. Coomes has published ${ }^{8}$ an account of his work on the pulsed properties of oxide cathodes. He produced evidence to show that (i) a cathode giving good results under D.c. conditions is not necessarily a good pulse cathode, (ii) there may be a large temperature rise when heavy currents are drawn, (iii) a major limitation on the maximum pulse current is the onset of 'sparking' or 'flashing', (iv) the effect of the composition of the core metal on pulse properties may be considerable, pure nickel probably being the best. Coomes suggests a different reason for the enhanced emission, namely, that the electrons thermally excited into the conduction band of the oxide semi-conductor during the period between pulses are swept out during the pulse and added to the normal emission for a short period.

Dr. Vick went on to discuss work by Eisenstein and his colleagues on the use of X-rays to study the structure of oxide cathodes ${ }^{2,10}$. The results show, inter alia, that the crystal size of the oxide depends mainly on the maximum temperature reached during activation, that during life the composition of the surface layers becomes nearly pure strontium oxide (confirming previous results), and that special interface compounds are often formed at the core-oxide boundary, associated with an interface resistance vs. current characteristic similar to that exhibited by barrier-layer rectifiers. These and other considerations have led some workers to picture an oxide cathode as made up of the following sections : $(a)$ metal core, $(b)$ rectifying barrier layer, with direction of easy flow towards the core, $(c)$ an excess semiconductor with dispersed interstitial barium, $(d)$ a 
region of strontium oxide with interstitial barium, (e) a surface potential barrier, the height of which may be influenced by an adsorbed barium layer. To determine the relative importance of the various factors and to fill in the details will require extensive work, both theoretical and experimental. Dr. Vick concluded the opening paper by outlining part of the programme of work recently commenced at the University of Manchester. C. A. Walley is applying the mass-spectrograph technique to identify the positive and negative ions emitted from oxide cathodes during activation and at all stages of life, and to correlate the ion currents with cathode structure and thermionic properties. W. Grattidge is studying methods of forming oxide cathodes without starting with the carbonates or using an organic binder, the aim being to obtain coatings with relatively simple and reproducible physical structures.

The next paper was contributed by Mr. D. A. Wright, of the Research Laboratories, General Electric Co. Ltd., Wembley, who dealt first with the factors affecting total coating resistance. He has applied the Mott ${ }^{11}$ and Schottky ${ }^{12}$ theories of barrierlayer rectification to the core-oxide interface. A potential barrier is to be expected at the interface, the difference between the work functions of the metal and of the oxide semi-conductor giving its height. The flow of electrons from core to oxide is then determined by barrier height, temperature, potential gradient through the barrier and the electron mobility in it. Mr. Wright's experiments using a magnesium-nickel core and a single probe embedded in the oxide have confirmed the existence of the barrier layer, with an effective resistance at low currents of 2-4 ohms per sq. cm., rising to tens of ohms at saturation. Hence at high currents the P.D. across the barrier layer can rise to some hundreds of volts, possibly leading to dielectric breakdown. The barrier layer may limit the emission available from the cathode, and its capacitance introduces a time-constant affecting changes in emission. Fineman and Eisenstein ${ }^{10}$ have shown that the true coating resistance away from the barrier layer is of the order of $1 \mathrm{ohm}$ per sq. $\mathrm{cm}$. To lower the true coating resistance in the presence of a high-resistance barrier layer would give little overall gain in performance, but if the barrier layer resistance could be lowered at the same time, a considerable gain would be possible.

With a magnesium-nickel core, the height of the potential barrier at the core interface has been estimated to be about $0.7 \mathrm{eV}$. Mr. Wright's recent calculations show that the bottom of the conduction bands in $\mathrm{BaO}, \mathrm{SrO}$ and $\mathrm{CaO}$ is not more than about $\mathbf{0 . 5} \mathrm{eV}$. below the zero-level. Conductivity measurements show that the impurity-levels of interstitial barium in barium oxide are between 1.0 and $1.5 \mathrm{eV}$. below the bottom of the conduction band. This gives a work function of $1 \cdot 0-1 \cdot 3 \mathrm{eV}$. Since this is of the same order as the observed work function for an oxide cathode, it indicates that any adsorbed barium on the surface has a small influence only on the work function. This is in agreement with the results of Nishibori and Kawamura ${ }^{13}$. In order to reconcile the value of the work function of the oxide with $4 \cdot 6 \mathrm{eV}$. for nickel and the barrier height of $0.7 \mathrm{eV}$., it seems necessary to assume the presence of barium at the core-oxide interface.

Treating the observed emission as from an excess semi-conductor, assuming that the concentration of interstitial barium is $5 \times 10^{17}$ atoms per c.c., the resistivity at $700^{\circ} \mathrm{C}$. is calculated to be $300 \mathrm{ohm}$. cm., and the saturated emission 50 amp. per sq. cm., agreeing reasonably well with experiment. Methods of reducing effective resistance are being explored in the G.E.C. Research Laboratories.

Mr. Wright concluded his paper by suggesting a reason for the most effective cathodes being those with approximately equimolecular proportions of barium and strontium oxides. The reasoning is based on a minimum work function for interstitial barium in the surface layers of strontium oxide.

These two opening papers provoked a lively discussion which raised many points of detail for which there is no space in this brief summary. Mr. T. J. Jones (Admiralty Signals Establishment) directed attention to additional arguments in favour of an adsorbed barium layer being a predominant factor in controlling the effective thermionic emission. In one of his experiments ${ }^{14}$ the outer layers only of an activated cathode were removed in a vacuum; this caused the emission to fall to about one thousandth. Subsequent operation at a suitable temperature restored the activity. Mr. Wright said that his own work and that of others had now stressed the importance of the core-oxide interface.

The last paper was contributed by Mr. A. J. H. Darlaston, of the Cosmos Manufacturing Co. Ltd., who gave a brief account of the preparation of oxide cathodes.

A fuller account of the proceedings at the meeting will be published in The Journal of Scientific Instruments. F. A. VIOK

1 Koller, L. R., Phys. Rev., 25, 671 (1925).

' Becker, J. A., Phys. Rev., 34, 1323 (1929).

${ }^{3}$ Becker, J. A., and Sears, R. W., Phys. Rev., 38, 2193 (1931).

- Reimann, A. L., "Thermionic Emission" (1934), 212.

${ }^{5}$ Lowry, E. F., Phys. Rev., 35, 1367 (1930).

- Relmann, A. L., and Murgoci, R., Phil. Mag., 9, 440 (1930).

' Sproull, R. L., Phys. Rev., 67, 166 (1945).

' Coomes, E. A., J. Appl. Phys., 17, 647 (1946).

- Eisenstein, A., J. Appl. Phys., 17, 434 and 654 (1946).

${ }^{10}$ Fineman, A., and Eisenstein, A., $J$. Appl. Phys., 17, 663 (1946)

11 Mott, N. F., Proc. Roy. Soc., A, 171, 27 (1939).

12 Schottky, W., Z. Phys., 113, 367 (1939) and 118, 539 (1942); Phys Z., 41, 539 (1940).

18 Nishibori and Kawamura, Phys. Math. Soc. Japan, 22, 378 (1940). "Jones, T. J., "Thermionic Emission", 82' (1936).

Gentrat :

Blewett, J. P., J. Appl. Phys., 10, 668 and 881 (1939); 17, 643 (1946)

Vick, F. A., Sci. Prog., 35, 82 (1947)

Weinreich, O., Rev. Gen. Elect., 46, 75 (1947).

Hermann, G., and Wagener, S., "Die Oxydkathode" (1944).

\section{TYPHUS RESEARCH}

$\mathrm{T}$ recent years research upon typhus has provided one of the best examples of the beneficent effects of international co-operation in scientific work. By agreement with workers in the United States and Canada, publication of many aspects of the work done on typhus at the National Institute for Medical Research, London, and at the Royal Army Medical College Emergency Vaccine Laboratory, Everleigh, Wilts, has been withheld. A full account of important parts of this work has now been issued*.

The researches of twelve workers are here recorded and Dr. C. H. Andrewes contributes a general introduc.

* Medical Research Council. Special Report Series, No. 255 : Chemotherapeutic and Other Studies of Typhus. By M. van den Ende, C. H. Stuart-Harris, F. FuIton and J. S. F. Niven, with C. H. Andrewes A. M. Begg, W. J. Elford, M. H. Gleeson White, W. I. Andrewes, A. C. Mills, F. Hamilton and C. C. Thomas. Pp. ii $+246+$ 11 plates. (London: H.M. Stationery Office, 1946.) 128. 6d. net. 